\title{
Inhibition of JAK2/STAT3 and activation of caspase-9/3 are involved in KYS05090S-induced apoptosis in ovarian cancer cells
}

\author{
BO-IM KIM ${ }^{1 *}$, JU-HA KIM $^{1 *}$, DEOK YONG SIM $^{1}$, MINHO NAM $^{1}$, JI HOON JUNG $^{1}$, \\ BUMSANG SHIM ${ }^{1}$, JAEYEOL LEE ${ }^{2}$ and SUNG-HOON KIM ${ }^{1}$ \\ ${ }^{1}$ Department of Pathology, College of Korean Medicine, Graduate School, \\ ${ }^{2}$ Research Institute for Basic Sciences and Department of Chemistry, \\ College of Sciences, Kyung Hee University, Seoul 02447, Republic of Korea
}

Received July 3, 2018; Accepted April 10, 2019

DOI: $10.3892 /$ ijo.2019.4795

\begin{abstract}
To overcome the poor prognosis of patients with ovarian cancer, attempting to target ovarian cancer with effective antitumor compounds has been conducted for numerous years. Although the 3,4-dihydroquinazoline derivative KYS05090S was known to exert antitumor effects in A549 and ovarian cancer cells by inhibition of T-type $\mathrm{Ca}^{2+}$ channels, the complete underlying antitumor mechanism of this compound remains unclear. Thus, in the present study, the potential apoptotic mechanism of KYS05090S was elucidated in SKOV3 and OVCAR3 ovarian cancer cells. KYS05090S exerted significant cytotoxicity in SKOV3 and OVCAR3 ovarian cancer cells, and also increased the number of apoptotic bodies, and the number of terminal deoxynucleotidyl transferase dUTP nick end labeling positive cells and the sub-G1 population as a feature of apoptosis. Consistently, KYS05090S induced cleavage of poly(ADP-ribose) polymerase and caspase-9/3 in ovarian cancer cells. Notably, KYS05090S attenuated the expression of anti-apoptotic proteins, including cyclin D1 and B-cell lymphoma-2 (Bcl-2), and reduced the phosphorylation of Janus kinase 2 (JAK2) and signal transducer and activator of transcription 3 (STAT3) in ovarian cancer cells. Additionally, KYS05090S blocked the nuclear translocation
\end{abstract}

Correspondence to: Professor Sung-Hoon Kim, Department of Pathology, College of Korean Medicine, Kyung Hee University, 26 Kyungheedae-ro, Seoul 02447, Republic of Korea

E-mail: sungkim7@khu.ac.kr

*Contributed equally

Abbreviations: IL-6, interleukin-6; JAK2, Janus kinase 2; STAT3, signal transducer and activator of transcription 3; PARP, poly(ADP-ribose) polymerase; BSA, bovine serum albumin

Key words: KYS05090S, ovarian cancer, apoptosis, JAK2, STAT3, IL-6 of STAT3 and suppressed the signaling of JAK2/STAT3 in interleukin-6-treated SKOV3 cells, as a STAT3 activator. Overall, these observations indicated that inhibition of JAK2/STAT3 signaling and activation of caspase-9/3 are critically involved in the effects of KYS05090S on apoptosis in ovarian cancer types, and the compound may be beneficial as a potent antitumor agent.

\section{Introduction}

Ovarian cancer is the fifth leading cause of cancer-associated mortality in females, with 152,000 mortalities globally according to The World Ovarian Cancer Coalition Atlas 2018 (1). Despite significant advances in surgical treatment and chemotherapy for ovarian cancer, 50-70\% of patients relapse within a year (2). To improve poor outcomes recently, targeted therapy has become an attractive option for ovarian cancer treatment (3). Additionally, sphingosine 1 phosphate (4), phosphoinositide 3-kinase/protein kinase B/mechanistic target of rapamycin $(5,6)$ and receptor tyrosine kinase like orphan receptor 1 (7) signaling have been reported to be molecular targets for ovarian cancer therapy.

Particularly, it is well established that signal transducer and activator of transcription 3 (STAT3) is involved in cancer progression, differentiation, proliferation, survival, apoptosis, angiogenesis and the immune system $(8,9)$.

Additionally, accumulating evidence revealed that selective blockers of T-type $\mathrm{Ca}^{2+}$ channels have anticancer potential, as $\mathrm{T}$-type $\mathrm{Ca}^{2+}$ channels are overexpressed in ovarian, lung and pancreatic cancer types $(10,11)$. In a recent study, eight compounds, including KYS05090S, exhibited significant cytotoxicity in SKOV3 cells, which is more potent than mibefradil regardless of T-type channel blocking activity (12). Novel fluoro-substituted 3,4-dihydroquinazoline derivative KYS05090S was reported to induce autophagy and apoptosis by generating reactive oxygen species, and inhibition of T-type $\mathrm{Ca}^{2+}$ channels and glucose uptake in human lung adenocarcinoma A549 cells (13); however, the underlying mechanism of KYS05090S in ovarian cancer is not fully understood. 
Thus, in the present study, the apoptotic mechanism of KYS05090S in association with Janus kinase 2 (JAK2) and downstream STAT3 signaling was investigated in ovarian cancer cells.

\section{Materials and methods}

Chemical and reagents. KYS05090S (molecular weight, $626.69 \mathrm{~g} / \mathrm{mol}$; molecular formula, C37H45Cl2N5O) $(10,14)$ was synthesized and supplied by Professor Jae Yeol Lee (Research Institute for Basic Sciences and Department of Chemistry, College of Sciences, Kyung Hee University, Seoul, Korea; Fig. 1A). Interleukin-6 (IL-6) was purchased from R\&D Systems, Inc. (Minneapolis, MN, USA). Ribonuclease A (RNase; cat. no. R6513) was purchased from Sigma-Aldrich (Merck KGaA, Darmstadt, Germany). DC Protein Assay kit II (cat. no. 500-0113) for the protein quantification during Western blotting was purchased from Bio-Rad Laboratories, Inc. (Hercules, CA, USA). DMSO, propidium iodide (PI), bovine serum albumin (BSA) and formaldehyde solution were obtained from Sigma-Aldrich (Merck KGaA).

Cell culture. Ovarian cancer cell lines SKOV3 (cat. no. ATCC ${ }^{\circledR}$

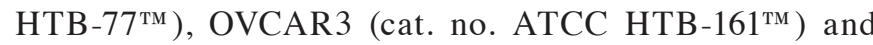
HEK293 cells (cat. no. ATCC CRL-1573 ${ }^{\mathrm{TM}}$ ) were obtained from the American Type Culture Collection (Manassas, VA, USA). These cells were cultured in Dulbecco's modified Eagle's medium (DMEM) supplemented with $10 \%$ fetal bovine serum and $1 \%$ antibiotic (Welgene, Inc., Gyeongsan, South Korea) at $37^{\circ} \mathrm{C}$ in a humid environment containing $5 \% \mathrm{CO}_{2}$.

Cell viability assay. To evaluate the cytotoxicity of KYS0590S, SKOV3 and OVCAR3 ovarian cancer, and HEK293 cells were seeded onto 96 -well tissue culture plates $\left(1 \times 10^{4}\right.$ cells/well) and were exposed to various concentrations $(0,1.5,3,6$ and $12 \mu \mathrm{M})$ of KYS0590S at $37^{\circ} \mathrm{C}$ for $24 \mathrm{~h}$. Subsequently, MTT solution $(1 \mathrm{mg} / \mathrm{ml})$ was added to each well for $1-2 \mathrm{~h}$ at $37^{\circ} \mathrm{C}$ in the dark and dimethyl sulfoxide was then added to each well at room temperature for $10 \mathrm{~min}$. Optical density (OD) was measured using a microplate reader (Molecular Devices, LLC, Sunnyvale, CA, USA) at a wavelength of $570 \mathrm{~nm}$. Cell viability was calculated as a percentage of viable cells in the KYS0590S-treated group, compared with the untreated control.

Terminal deoxynucleotidyl transferase dUTP nick end labeling (TUNEL) assay. DNA fragmentation was analyzed using an In Situ Cell Death Detection kit (Roche Diagnostics, Basel, Switzerland). SKOV3 and OVCAR3 cells $\left(4 \times 10^{4}\right.$ cells/well) were plated onto 4 well Chamber slides (SPL Life Sciences, Pocheon, South Korea) and exposed to KYS05090S $(5 \mu \mathrm{M})$ at $37^{\circ} \mathrm{C}$ for $24 \mathrm{~h}$. The cells were fixed in $4 \%$ paraformaldehyde at room temperature for $1 \mathrm{~h}$ and treated with TUNEL buffer containing fluorescein isothiocyanate fluorescein-12-dUTP for $1 \mathrm{~h}$ at $37^{\circ} \mathrm{C}$ in the dark. The slides were mounted with mounting medium containing DAPI (Vector Laboratories, Inc., Burlingame, CA, USA) and visualized at x200 magnification using FLUOVIEW FV10i confocal microscopy (Olympus Corporation, Tokyo, Japan) in three fields of view.

Sub-G1 accumulation by cell cycle analysis. SKOV3 and OVCAR3 cells were treated with KYS05090S $(0,3$ and $5 \mu \mathrm{M})$ at $37^{\circ} \mathrm{C}$ for $24 \mathrm{~h}$ and washed with PBS three times. Ethanol $(70 \%)$ was used to fix the cells at $4^{\circ} \mathrm{C}$ overnight. The cells were treated with RNase $(1 \mathrm{mg} / \mathrm{ml})$ at $37^{\circ} \mathrm{C}$ for $1 \mathrm{~h}$, stained with PI at $37^{\circ} \mathrm{C}$ for $1 \mathrm{~h}$ and then quantified using a FACS Caliber flow cytometer and CellQuest software Version 5.2.1 (BD Biosciences; Becton Dickinson and Company, Franklin Lakes, NJ, USA).

Apoptosis detection by DAPI staining. SKOV3 and OVCAR3 cells were exposed to KYS05090S (3 and $5 \mu \mathrm{M}$ ) at $37^{\circ} \mathrm{C}$ for $24 \mathrm{~h}$. The ovarian cells were fixed in $4 \%(\mathrm{v} / \mathrm{v})$ methanol-free formaldehyde solution at room temperature for $1 \mathrm{~h}$. The slides were mounted, and nuclei were counterstained with DAPI (10 $\mu \mathrm{g} / \mathrm{ml}$; Sigma-Aldrich; Merck KGaA) solution for $25 \mathrm{~min}$ at room temperature in the dark, and were visualized at $\mathrm{x} 40$ and x63 magnification by Zeiss LSM700 confocal microscopy.

Immunofluorescence assay. SKOV3 cells $\left(5 \times 10^{4}\right.$ cells/well) were plated onto cell culture chamber slides (SPL Life Sciences) following serum-starvation (DMEM) at $37^{\circ} \mathrm{C}$ for $3 \mathrm{~h}$. The cells were treated with KYS05090S $(5 \mu \mathrm{M})$ at $37^{\circ} \mathrm{C}$ for $24 \mathrm{~h}$ and IL-6 $(30 \mathrm{ng} / \mathrm{ml})$ at $37^{\circ} \mathrm{C}$ for $15 \mathrm{~min}$, and then fixed in $4 \%(\mathrm{v} / \mathrm{v})$ methanol-free formaldehyde solution ( $\mathrm{pH} \mathrm{7.4)}$ at $4^{\circ} \mathrm{C}$ for $25 \mathrm{~min}$. Following permeabilization in $0.2 \%(\mathrm{v} / \mathrm{v})$ Triton X-100, the cells were blocked at room temperature for $1 \mathrm{~h}$ with $5 \%(\mathrm{v} / \mathrm{v})$ BSA, $0.5 \%(\mathrm{v} / \mathrm{v})$ Tween-20 in PBS and incubated with STAT3 antibody (cat. no. 12640; Cell Signaling Technology, Inc., Danvers, MA, USA; 1:1,000) at $4^{\circ} \mathrm{C}$ overnight. Anti-mouse IgG Alexa Fluor 488 (cat. no. A28175; Thermo Fisher Scientific, Inc., Waltham, MA, USA; 1:1,000) was used as the secondary antibody and incubated for $1 \mathrm{~h}$ at room temperature. The slides were mounted using mounting medium (Vector Laboratories, Inc.) and nuclei were counterstained with DAPI at room temperature for $15 \mathrm{~min}$. Subsequently, the slides were visualized under a FLUOVIEW FV10i confocal microscope (Olympus Corporation).

Western blot analysis. SKOV3 and OVCAR3 cells were lysed in Radioimmunoprecipitation assay buffer $(50 \mathrm{mM}$ Tris- $\mathrm{HCl}$, $150 \mathrm{mM} \mathrm{NaCl}, 2 \mathrm{mM}$ EDTA and 1\% Triton X-100) containing protease inhibitors (Roche Diagnostics GmbH, Mannheim, Germany), and phosphatase inhibitors (Sigma-Aldrich; Merck KGaA). Protein samples $(100 \mu \mathrm{g})$ were centrifuged at $15,000 \mathrm{x} \mathrm{g}$ and $4^{\circ} \mathrm{C}$ for $30 \mathrm{~min}$ and the supernatant was distributed into 96-well plate, exposed to the solutions of a DC protein assay kit at room temperature for $10 \mathrm{~min}$ and then the absorbance was detected at $665 \mathrm{~nm}$ with Bio-Rad model 680 ELISA reader. The protein was separated by SDS-PAGE on an $8 \%$ gel and an equal amount of protein was loaded on SDS-PAGE and transferred to nitrocellulose membranes. Membranes were blocked by 5\% skim-milk (diluted in TBST) solution at room temperature for $1 \mathrm{~h}$. Membranes were incubated with primary antibodies to detect cleaved-poly(ADP-ribose) polymerase (PARP; cat. no. 9542; 1:1,000), cleaved-caspase-3 (cat. no. 9664; 
A<smiles>CN(C)CCCCCN(C)C1=Nc2ccccc2C(CC(=O)NCc2ccccc2)N1c1ccc(-c2ccccc2)cc1</smiles>

$\mathrm{KYS} 05090 \mathrm{~S}\left(\mathrm{C}_{33} \mathrm{H}_{43} \mathrm{Cl}_{2} \mathrm{~N}_{9} \mathrm{O}\right)$

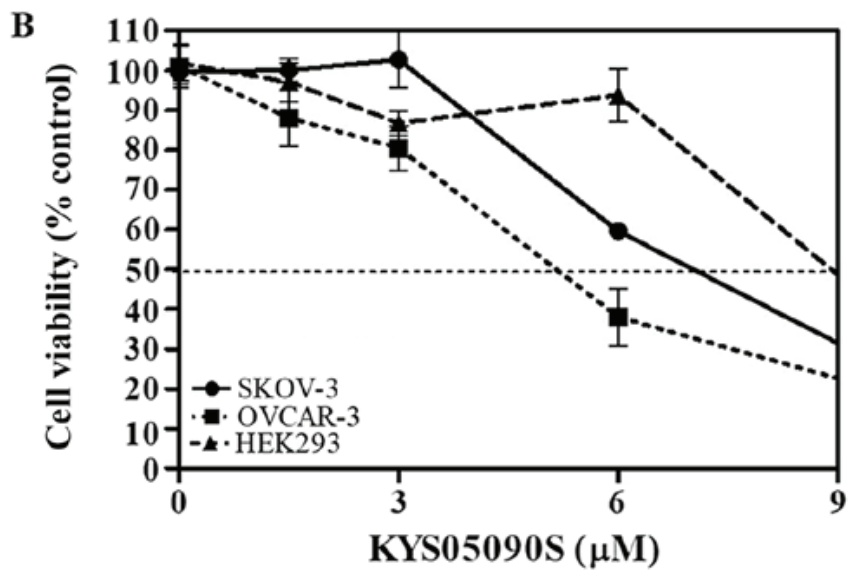

Figure 1. Chemical structure of KYS05090S and its cytotoxicity in ovarian cancer cells. (A) Chemical structure of KYS05090S (molecular weight, $626.69 \mathrm{~g} / \mathrm{mol}$; molecular formula, C37H45Cl2N5O). (B) Cytotoxicity of KYS05090S was evaluated in SKOV3 and OVCAR3 cancer cells, and HEK293 cells. The cells were exposed to various concentrations of KYS05090S for $24 \mathrm{~h}$ and then subjected to an MTT assay.

1:1,000), cleaved-caspase-9 (cat. no. 9505; 1:1,000), cyclin D1 (cat. no. 2978; 1:1,000), c-Myc (cat. no. 5605; 1:1,000), phospho (p)-JAK2 (cat. no. 3776s; 1:1,000), JAK2 (cat. no. 3230s; 1:1,000), p-STAT3 (cat. no. 9145; 1:1,000) and STAT3 (cat. no. 12640s; 1:1,000; all Cell Signaling Technologies, Inc.), B-cell lymphoma-2 (Bcl-2; cat. no. sc-492; 1:500; Santa Cruz Biotechnology, Inc., Dallas, TX, USA) and $\beta$-actin (cat. no. A2228; 1:10,000; Sigma-Aldrich; Merck KGaA) diluted in PBS-Tween-20 with $3 \%$ BSA overnight at $4^{\circ} \mathrm{C}$, washed three times with $0.2 \%$ PBS-Tween-20, and incubated with horseradish peroxidase-conjugated secondary anti-rabbit (cat. no. 7074; 1:5,000; Cell Signaling Technologies, Inc.) and anti-mouse (cat. no. sc-516102; 1:10,000; Santa Cruz Biotechnology, Inc.) IgG antibodies at $4{ }^{\circ} \mathrm{C}$ overnight. The blot expression was visualized with enhanced chemiluminescence (GE Healthcare Life Sciences, Little Chalfont, UK). Additionally, SKOV 3 cells were exposed to IL- 6 at $4^{\circ} \mathrm{C}$ for 15 min to activate the JAK2/STAT3 pathway.

Statistical analysis. Data are presented as the mean \pm standard deviation. All experiments were repeated at least three times. The statistically significant differences between control and KYS05090S treated groups were determined using one-way analysis of variance and Tukey post hoc test. $\mathrm{P}<0.05$ was considered to indicate a statistically significant difference by using GraphPad Prism 5 (GraphPad Software, Inc., La Jolla, CA, USA).

\section{Results}

KYS05090S exerts cytotoxic effects in SKOV3 and OVCAR3 ovarian cancer cells. The cytotoxicity of KYS05090S (Fig. 1A) was evaluated in SKOV3 and OVCAR3 ovarian cancer cells, and HEK293 cells. KYS05090S notably increased cytotoxicity in a concentration-dependent manner in SKOV3 and OVCAR3 cancer cells; whereas, it exhibited comparatively reduced cytotoxicity in normal HEK293 cells (Fig. 1B).

KYS05090S increases the number of apoptotic bodies, TUNEL positive cells and sub-G1 population in SKOV3 and OVCAR3 cells. Subsequently, to determine the apoptotic effect of KYS05090S, DAPI staining and a TUNEL assay were conducted in SKOV3 and OVCAR3 cells. Nuclei fragmentation, abnormal margins and condensed chromosomes were observed in KYS05090S-treated SKOV3 and OVCAR3 cells (Fig. 2A). To further investigate the KYS05090S-induced apoptosis, cell cycle analysis was performed, since the sub-G1 phase population exhibits DNA fragmentation and loss due to apoptosis (15). As expected, KYS05090S dose-dependently increased the sub-G1 cell population in SKOV3 and OVCAR3 ovarian cancer cells (Fig. 2B-D). Similarly, a TUNEL assay demonstrated that KYS05090S increased the number of TUNEL-positive SKOV3 and OVCAR3 cells, compared with untreated control cells (Fig. 2E).

KYS05090S regulates pro- and anti-apoptotic proteins in SKOV3 and OVCAR3 cells. To investigate the apoptotic mechanism of KYS05090S, western blot analysis was performed to determine the expression of pro- and anti-apoptotic proteins in SKOV3 and OVCAR3 cells. In the present study, KYS05090S treatment increased the cleavage of PARP, and activated caspase- 9 and caspase- 3 in the ovarian cancer cells, compared with untreated control cells (Fig. 3). Consistently, KYS05090S decreased the expression of anti-apoptotic proteins, including cyclin D1, Bcl-2 and Bcl-extra large (Bcl-xl) in OVCAR3 and SKOV3 cells (Fig. 4). Additionally, the level of p-STAT3 was significantly $(\mathrm{P}<0.05)$ attenuated by KYS05090S treatment in both ovarian cancer cell lines by KYS05090S treatment. KYS05090S treatment also dose-dependently reduced the level of p-JAK2 and c-Myc in SKOV3 cells (Fig. 4B).

KYSO5090S suppresses the phosphorylation of JAK2 and STAT3, and nuclear translocation of STAT3 in SKOV3 and OVCAR 3 cells. Subsequently, the role of JAK2/STAT3 signaling in KYS05090S-induced apoptosis in SKOV3 cells was investigated, as JAK2/STAT3 signaling is involved in cancer cell proliferation and progression (16). It is well established that IL-6 activates JAK2/STAT3 signaling (16-18). In the present study, p-JAK2 and p-STAT3 levels were increased by $30 \mathrm{ng} / \mathrm{ml}$ IL- 6 treatment and the phosphorylation effect was maximal at $15 \mathrm{~min}$ after IL-6 treatment (Fig. 5A). Therefore, SKOV3 cells were exposed to IL-6 for $15 \mathrm{~min}$ to activate the JAK2/STAT3 pathway in the subsequent 
A

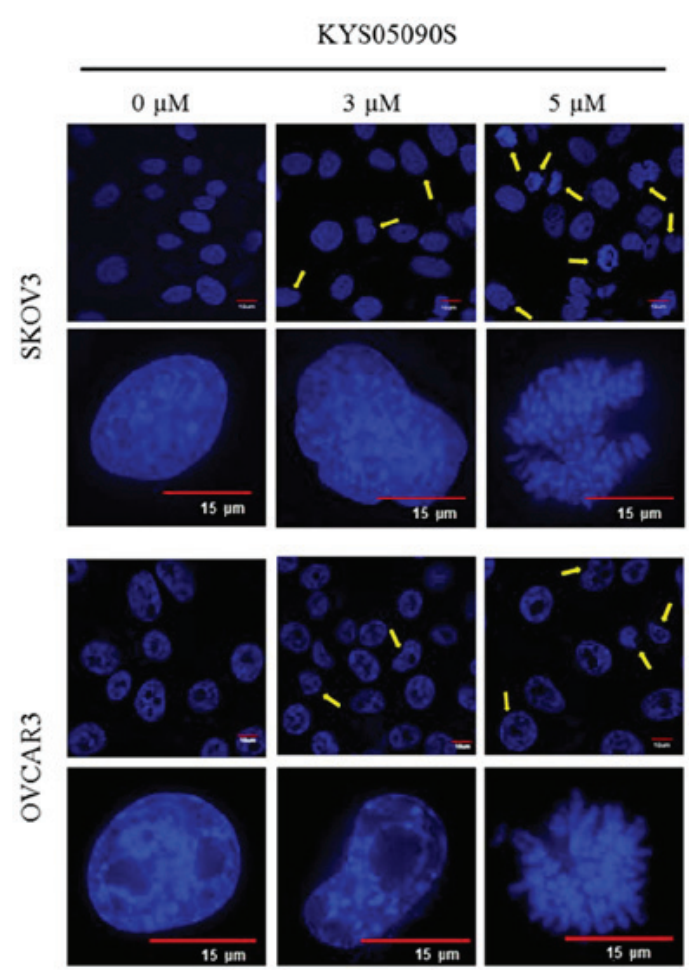

B
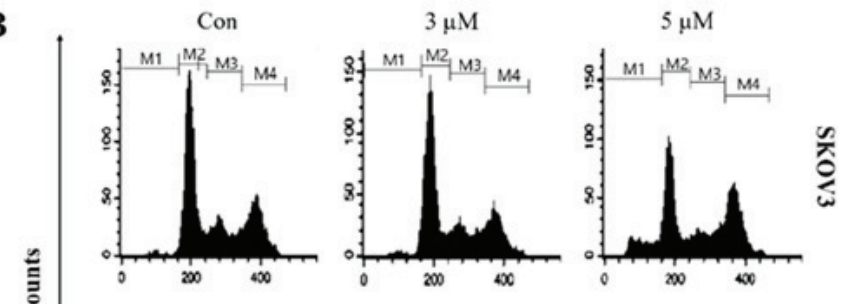

$\bar{\Xi}$

C

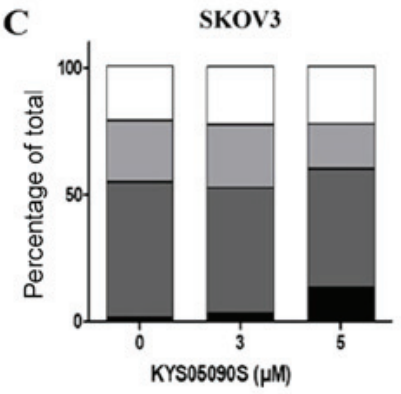

Fluorescence intensity

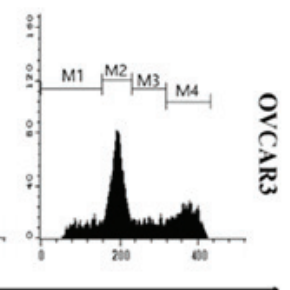

D

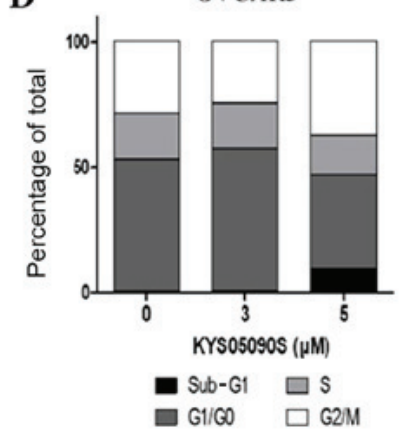

$\mathbf{E}$

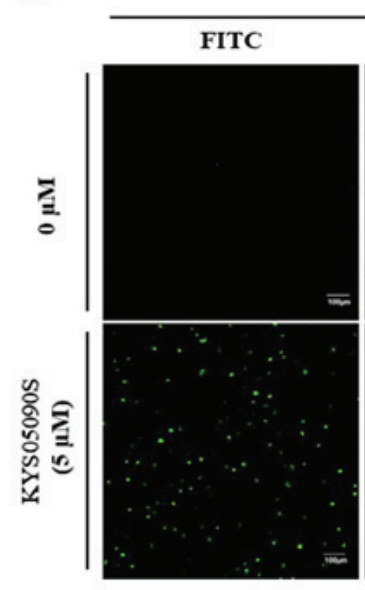

SKOV3
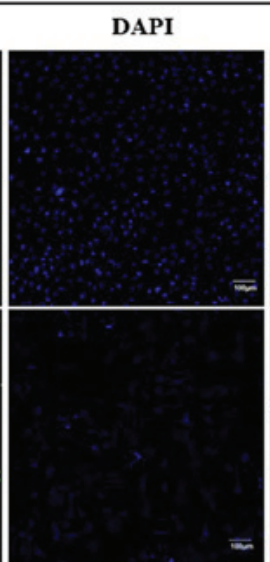
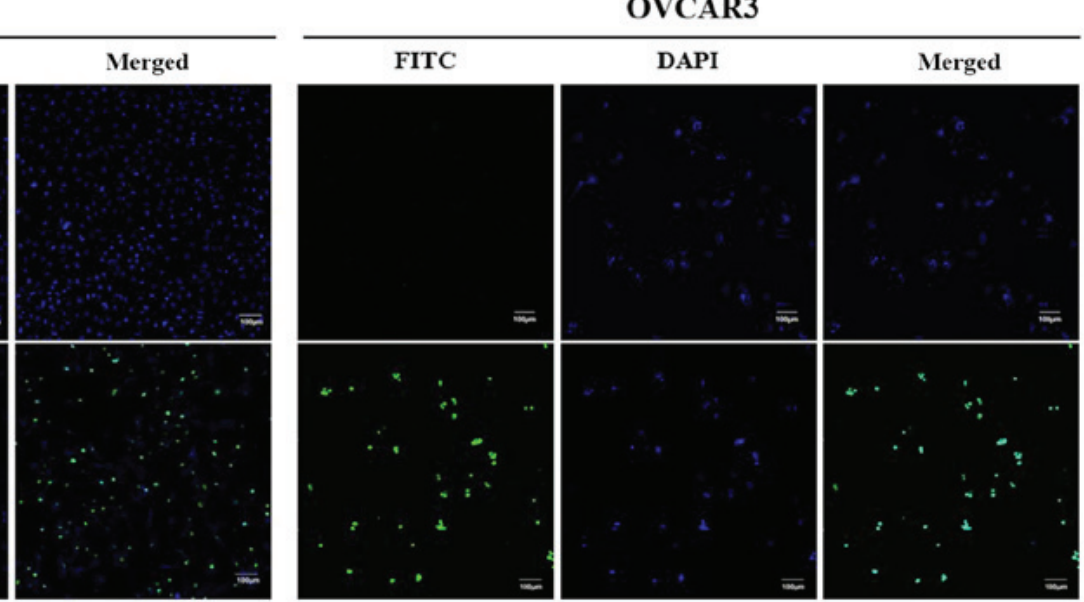

Figure 2. KYS05090S increases the number of apoptotic bodies, TUNEL-positive cells (FITC-fluorescence) and the sub-G1 population in ovarian cancer cells. (A) Apoptotic bodies in KYS05090S-treated SKOV3 and OVCAR3 cells by DAPI staining. Arrows indicate apoptotic bodies. Scale bars, 10 or $15 \mu \mathrm{m}$. (B) Sub-G1 population in KYS05090S-treated SKOV3 and OVCAR3 cells. Quantification of cell cycle phase in (C) SKOV3 and (D) OVCAR3 cells. (E) TUNEL-positive cells in KYS05090S-treated SKOV3 and OVCAR3 cells by TUNEL assay. Scale bar, $100 \mu \mathrm{m}$. TUNEL, terminal deoxynucleotidyl transferase dUTP nick end labeling; M1, sub-G1; M2, G1/G0; M3, S; M4, G2/M phase; FITC, fluorescein isothiocyanate; Con, control.

experiments. KYS05090S treatment significantly suppressed the IL-6-induced phosphorylation of JAK2 and its downstream mediator, STAT3, in SKOV3 cells ( $\mathrm{P}<0.05$; Fig. 5B).

Furthermore, nuclear translocation is essential for the anti-apoptotic function of STAT3 within the JAK2/STAT3 pathway (19). Therefore, immunofluorescence staining for STAT3 and PI staining were performed to observe nuclear translocation of STAT3 in SKOV3 cells. IL-6 treatment successfully induced STAT3 nuclear translocalization in SKOV3 cells ( $\mathrm{P}<0.05$; Fig. 6). However, KYS05090S treatment significantly reversed the increased nuclear translocation of STAT3 induced by IL-6, compared with untreated control cells.

\section{Discussion}

The treatment options for ovarian cancer have been limited to surgery (for stage I-IVA epithelial ovarian cancer), chemotherapy (primarily using paclitaxel, docetaxel and carboplatin or bevacizumab), immunotherapy and hormonal therapy $(20,21)$. Despite improvements in early detection and 


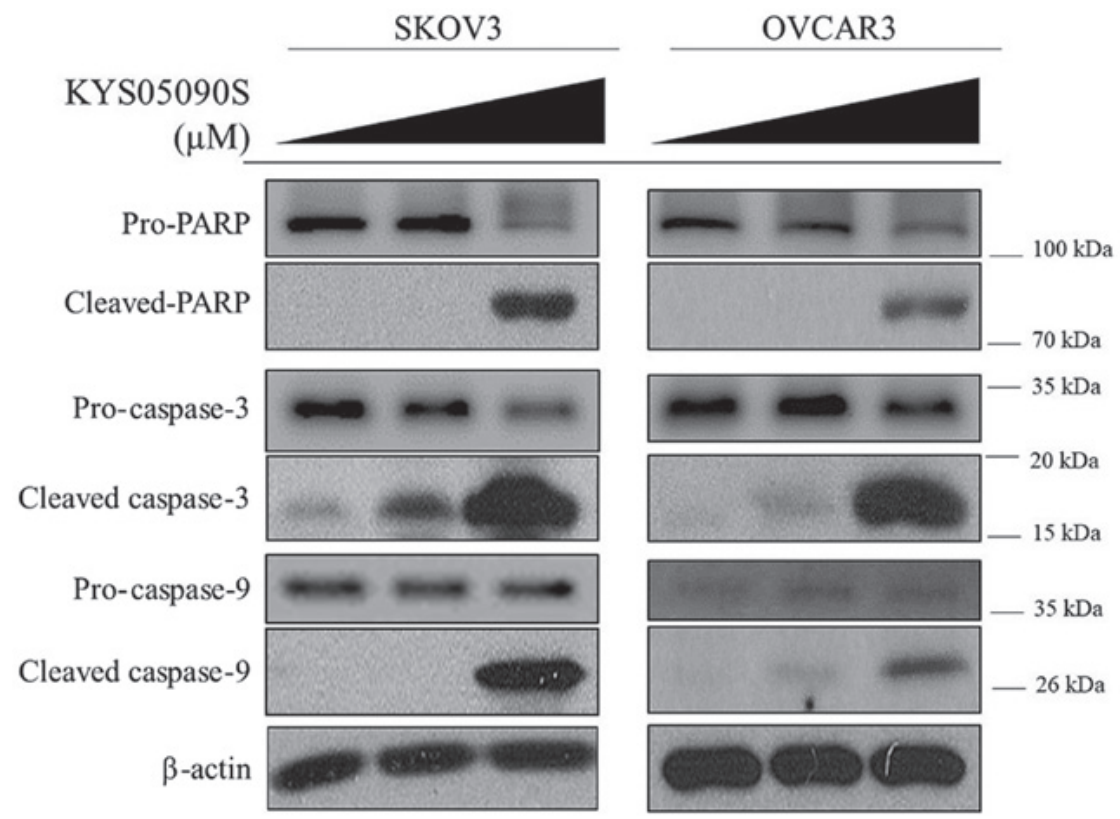

Figure 3. KYS05090S induces cleavage of PARP, and caspase-3 and -9 in ovarian cancer cells. SKOV3 and OVCAR3 cells were exposed to KYS05090S (3 and $5 \mu \mathrm{M})$ and subjected to western blot analysis with antibodies against PARP, caspase-3, caspase-9 and $\beta$-actin. PARP, poly(ADP-ribose) polymerase.

A

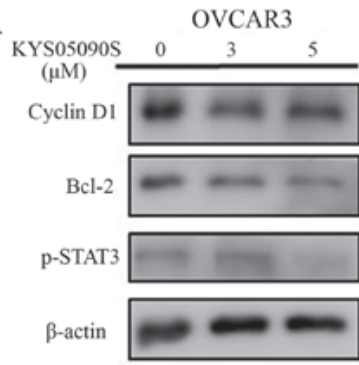

B

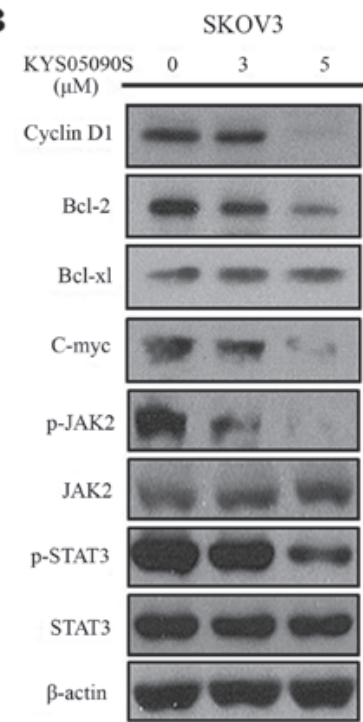

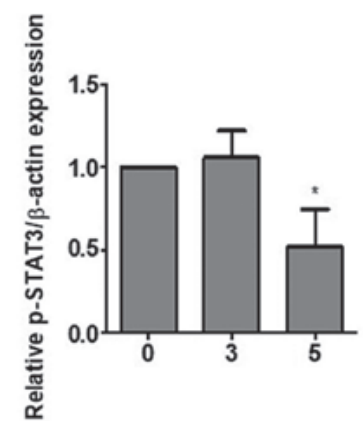

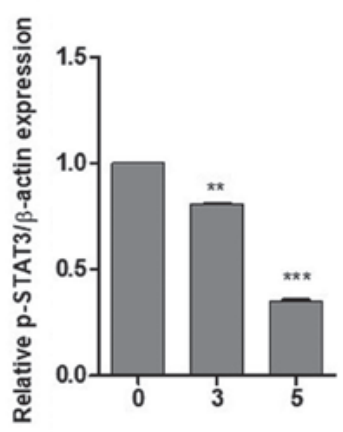

Figure 4. KYS05090S reduces the expression of anti-apoptotic proteins in ovarian cancer cells. (A) OVCAR3 cells were exposed to KYS05090S (3 and $5 \mu \mathrm{M}$ ) for $24 \mathrm{~h}$ and subjected to western blot analysis with antibodies against cyclin D1, Bcl-2 and p-STAT3. (B) SKOV3 cells were exposed to KYS05090S ( 3 and $5 \mu \mathrm{M}$ ) for $24 \mathrm{~h}$ and subjected to western blotting with antibodies against cyclin D1, Bcl-2, Bcl-xl, c-Myc, p-JAK2, JAK2, STAT3, p-STAT3 and $\beta$-actin ${ }^{*} \mathrm{P}<0.05,{ }^{* *} \mathrm{P}<0.01$ and ${ }^{* * * *} \mathrm{P}<0.001$ vs. untreated control by Student's t-test. Bcl-2, B-cell lymphoma-2; Bcl-xl, B-cell lymphoma-extra large; p-, phospho-; JAK2, Janus kinase 2; STAT3, signal transducer and activator of transcription 3.

development of potential effective therapeutics for ovarian cancer, the prognosis of patients following treatment is considered poor (22); therefore, more effective anticancer agents are required for ovarian cancer therapy.

The T-type $\mathrm{Ca}^{2+}$ channel blocker KYS05090S was previously reported to induce autophagy and apoptosis in A549 non-small lung cancer cells (10). In the present study, the underlying anticancer mechanism of KYS05090S was investigated in ovarian cancer cell lines.

KYS05090S exerted significant cytotoxicity in SKOV3 and OVCAR3 cells, which was increased compared with HEK293 cells. To confirm whether the cytotoxicity of KYS05090S is attributed to its apoptotic effect, DAPI staining, a TUNEL assay and cell cycle analysis were conducted. As expected, KYS05090S treatment increased the number of DAPI- and TUNEL-positive cells, and increased the sub-G1 population in SKOV3 and OVCAR3 cells, indicating the apoptotic effect of KYS05090S.

In general, two major apoptotic pathways have been well established: The intrinsic (mitochondrial-mediated) pathway and the extrinsic (death receptor-dependent) pathway, which result in caspase activation $(23,24)$. The intrinsic apoptotic pathway causes the activation of caspase- 9 and the extrinsic pathway is mediated by the activation of caspase-8 (25). The western blot analysis in the present study demonstrated that KYS05090S induced PARP cleavage and activation of caspase-9/3, but not caspase- 8 activation (data not shown), in SKOV3 and OVCAR3 cells, indicating that apoptosis induced by KYS05090S treatment is mediated primarily via the intrinsic pathway.

During the intrinsic pathway, activation of pro-apoptotic $\mathrm{Bcl}-2$ family proteins subsequently inactivate anti-apoptotic Bcl-2 proteins (26). In the present study, KYS05090S attenuated the expression of cyclin D1, c-Myc, Bcl-xl and Bcl-2 as anti-apoptotic proteins. It is well documented that JAK2/STAT3 signaling is critically involved in cancer progression, proliferation, differentiation, apoptosis, oncogenesis and immunity (16,27-29). 


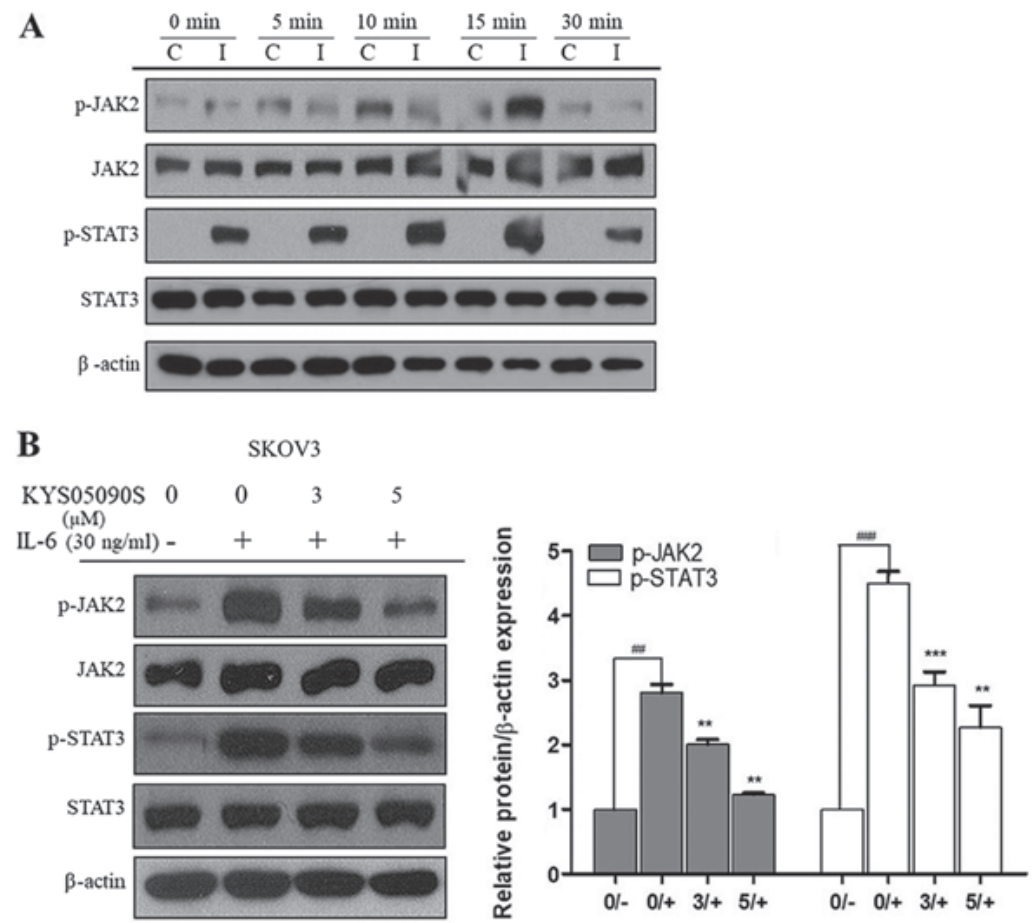

Figure 5. KYS05090S suppresses the phosphorylation of JAK2 and STAT3 in IL-6-treated SKOV3 ovarian cancer cells. (A) Time-dependent effect of IL-6 on the phosphorylation of JAK2 and STAT3 in SKOV3 cells. (B) Effect of KYS05090S on phosphorylation of JAK2 and STAT3 in SKOV3 cells in the presence or absence of IL-6. After $3 \mathrm{~h}$ starvation, SKOV3 cells were exposed to IL-6 for $15 \mathrm{~min}$ and then treated with KYS05090S $(3$ or $5 \mu \mathrm{M})$ for $24 \mathrm{~h}$. ${ }^{\# \# P} \mathrm{P}<0.01$,

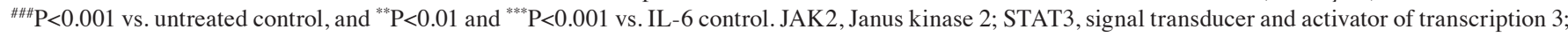
IL-6, interleukin-6; C, control; I, IL-6 (30 ng/ml); p-, phospho-.
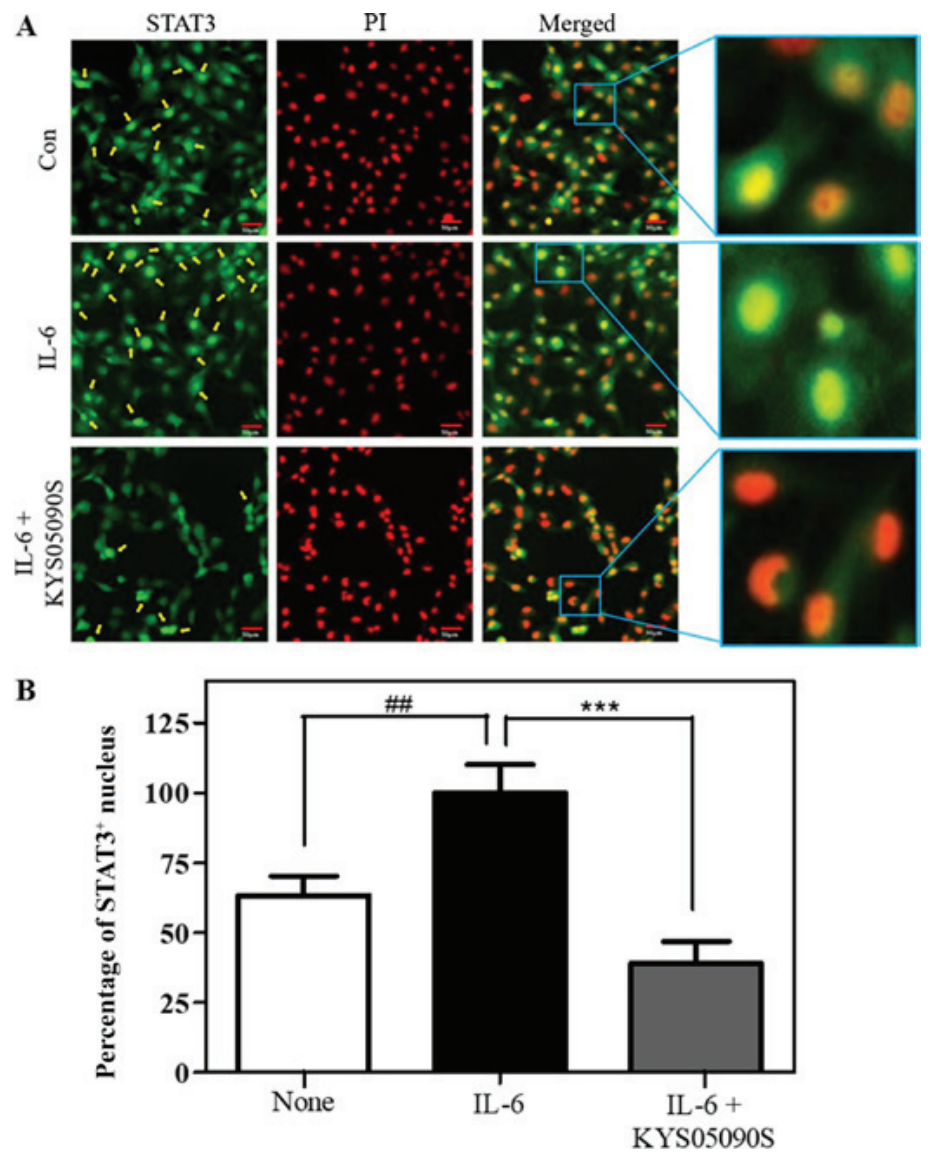

Figure 6. KYS05090S blocks IL-6-induced nuclear translocation of STAT3 in SKOV3 ovarian cancer cells. (A) Representative confocal images of STAT3 (green)-stained SKOV3 cells. After $3 \mathrm{~h}$ starvation, SKOV3 cells were exposed to IL-6 for 15 min and then treated by KYS05090S for $24 \mathrm{~h}$. Arrows indicate nuclear translocated cells. Scale bar, $50 \mu \mathrm{m}$. (B) Quantification of STAT3-positive cells. ${ }^{\# \#} \mathrm{P}<0.01$ vs. untreated control; ${ }^{* * *} \mathrm{P}<0.001$ vs. IL-6 control. STAT3, signal transducer and activator of transcription 3; IL-6, interleukin-6; PI, propidium iodide. 


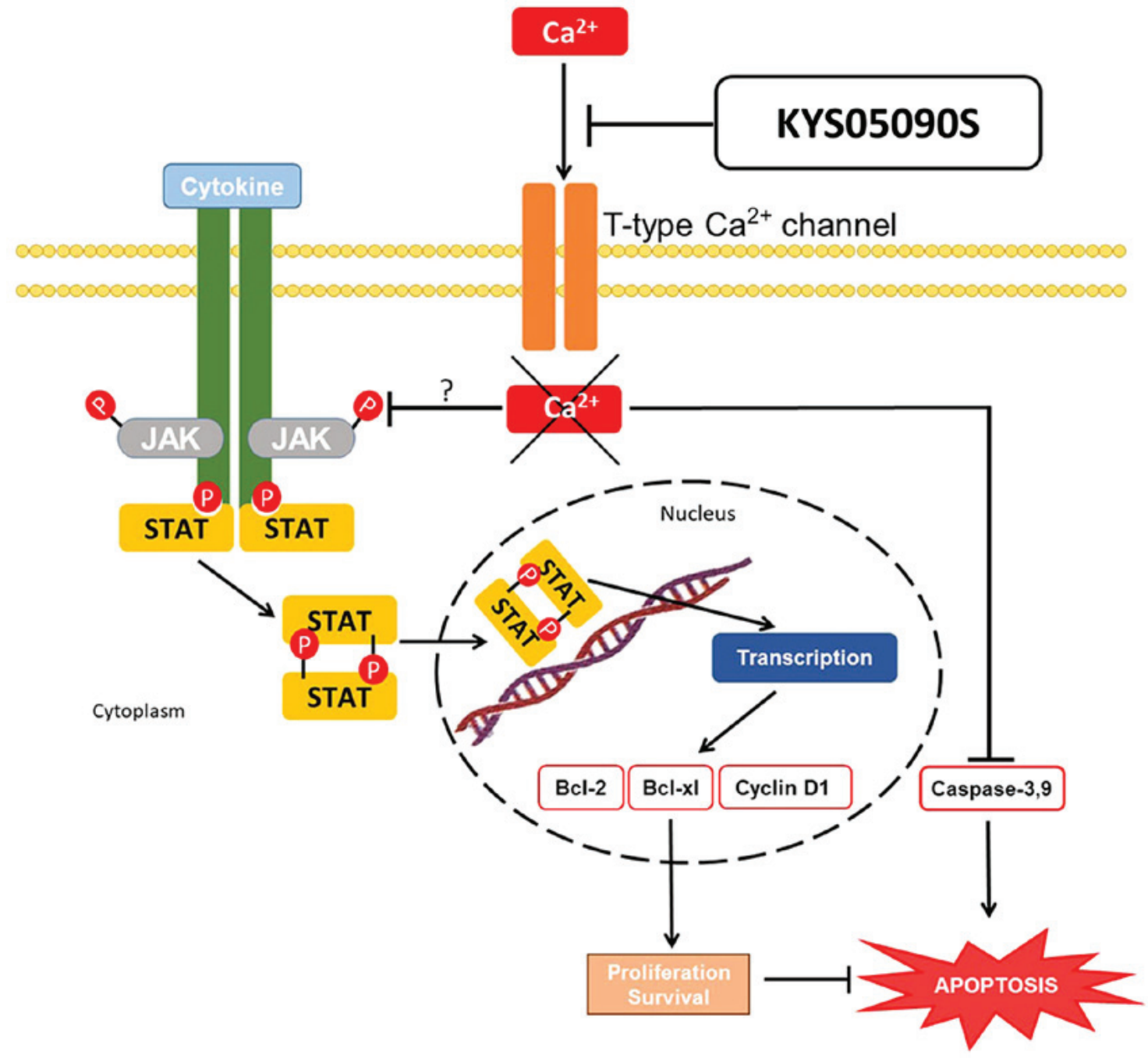

Figure 7. Apoptotic mechanism of KYS05090S in ovarian cancer cells via the JAK2/STAT3 signaling pathway. JAK2, Janus kinase 2; STAT3, signal transducer and activator of transcription 3; P, phosphate; Bcl-2, B-cell lymphoma-2; Bcl-xl, B-cell lymphoma-extra large.

Furthermore, STAT3 dimerization and its transcriptional activity are known to inhibit cell growth and induce apoptosis (29). Additionally, accumulating evidence has revealed that IL-6 directly activates the JAK2/STAT3 signaling pathway $(16,30)$, which suppresses major histocompatibility complex class II expression on DC and $\mathrm{CD}^{+}{ }^{+}$Th cells during immune responses through activation of lysosomal protease (31). Serum IL-6 levels are also associated with the tumor stage and size, metastasis and survival of patients with colon cancer (32). Notably, in the present study, KYS05090S suppressed the phosphorylation of JAK2 and its downstream mediator STAT3 in SKOV3 and OVCAR3 cells, and also blocked nuclear translocation of STAT3 even in IL-6-treated SKOV3 cells, indicating that the JAK2/STAT3 signaling pathway has a crucial role in the effects of KYS05090S (33). Nonetheless, considering that the half maximal inhibitory concentration of the T-type $\mathrm{Ca}^{2+}$ channel blocker-KYS05090S was reported to be $0.51 \pm 0.02 \mu \mathrm{M}$ in A549 cells (10), KYS05090S may be a multi-target compound, including JAK2/STAT3 pathway components, $\mathrm{Ca}^{2+}$ channels and other targets. Taking previous evidence from 3,4-dihydroquinazoline derivatives into consideration (34), further study is required for determining nontoxic optimal doses in animals and to identify the mechanism of KYS05090S along with pharmacokinetics and DMEM studies for future clinical trials.

Overall, the T-type $\mathrm{Ca}^{2+}$ channel blocker KYS05090S significantly increased cytotoxicity, the number of apoptotic bodies and sub-G1 cellular population, activated PARP cleavage and caspase-9/3, and reduced the protein levels of cyclin D1, Bcl-2 and p-JAK2/p-STAT3 in SKOV3 and OVCAR3 cells. Furthermore, KYS05090S blocked the nuclear translocation of STAT3 and suppressed phosphorylation of JAK2/STAT3 in IL-6-treated SKOV3 cells. Collectively, the data support that KYS05090S induces apoptosis via activation of caspase-9/3 and inhibition of JAK2/STAT3 signaling in ovarian cancer cells, and may be used as a potent antitumor agent (Fig. 7).

\section{Acknowledgements}

Not applicable.

\section{Funding}

This work was supported by the National Research Foundation of Korea grant funded by the Korea Government (grant no. 2017R1A2A1A17069297). 


\section{Availability of data and materials}

The datasets used and/or analyzed during the current study are available from the corresponding author on reasonable request.

\section{Authors' contributions}

BIK and JHK conducted analysis and interpretation of data and contributed to drafting the manuscript. BIK, JHK, DYS, MN, JHJ, BS and JL designed and performed the experiments for acquisition of data. SHK made acquisition of funding, conception, design and supervision for this study. JL synthesized and supplied KYS05090S. All authors read and approved the final manuscript.

\section{Ethics approval and consent to participate}

Not applicable.

\section{Patient consent for publication}

Not applicable.

\section{Competing interests}

The authors declare that they have no competing interests.

\section{References}

1. Coward JI, Middleton K and Murphy F: New perspectives on targeted therapy in ovarian cancer. Int J Womens Health 7 : 189-203, 2015.

2. Yan H, Guo BY and Zhang S: Cancer-associated fibroblasts attenuate Cisplatin-induced apoptosis in ovarian cancer cells by promoting STAT3 signaling. Biochem Biophys Res Commun 470: 947-954, 2016.

3. Lim HJ and Ledger W: Targeted therapy in ovarian cancer. Wom Health Lond 12: 363-378, 2016.

4. Dai L, Xia P and Di W: Sphingosine 1-phosphate: A potential molecular target for ovarian cancer therapy? Cancer Invest 32: 71-80, 2014.

5. Mabuchi S, Kuroda H, Takahashi R and Sasano T: The $\mathrm{PI} 3 \mathrm{~K} / \mathrm{AKT} / \mathrm{mTOR}$ pathway as a therapeutic target in ovarian cancer. Gynecol Oncol 137: 173-179, 2015.

6. Cheaib B, Auguste A and Leary A: The PI3K/Akt/mTOR pathway in ovarian cancer: Therapeutic opportunities and challenges. Chin J Cancer 34: 4-16, 2015.

7. Zhang S, Cui B, Lai H, Liu G, Ghia EM, Widhopf GF II, Zhang Z, Wu CC, Chen L, Wu R, et al: Ovarian cancer stem cells express ROR1, which can be targeted for anti-cancer-stem-cell therapy. Proc Natl Acad Sci USA 111: 17266-17271, 2014.

8. Horvath CM: STAT proteins and transcriptional responses to extracellular signals. Trends Biochem Sci 25: 496-502, 2000.

9. Siddiquee K, Zhang S, Guida WC, Blaskovich MA, Greedy B, Lawrence HR, Yip ML, Jove R, McLaughlin MM, Lawrence NJ, et al: Selective chemical probe inhibitor of Stat3, identified through structure-based virtual screening, induces antitumor activity. Proc Natl Acad Sci USA 104: 7391-7396, 2007.

10. Rim HK, Cho S, Shin DH, Chung KS, Cho YW, Choi JH, Lee JY and Lee KT: T-type $\mathrm{Ca}^{2+}$ channel blocker, KYS05090 induces autophagy and apoptosis in A549 cells through inhibiting glucose uptake. Molecules 19: 9864-9875, 2014.

11. Dziegielewska B, Gray LS and Dziegielewski J: T-type calcium channels blockers as new tools in cancer therapies. Pflugers Arch 466: 801-810, 2014

12. Jang SJ, Choi HW, Choi DL, Cho S, Rim HK, Choi HE, Kim KS, Huang M, Rhim H, Lee KT, et al: In vitro cytotoxicity on human ovarian cancer cells by T-type calcium channel blockers. Bioorg Med Chem Lett 23: 6656-6662, 2013.
13. Jung SY, Lee SH, Kang HB, Park HA, Chang SK, Kim J, Choo DJ, Oh CR, Kim YD, Seo JH, et al: Antitumor activity of 3,4-dihydroquinazoline dihydrochloride in A549 xenograft nude mice. Bioorg Med Chem Lett 20: 6633-6636, 2010.

14. Byun JS, Sohn JM, Leem DG, Park B, Nam JH, Shin DH, Shin JS, Kim HJ, Lee KT and Lee JY: In vitro synergistic anticancer activity of the combination of T-type calcium channel blocker and chemotherapeutic agent in A549 cells. Bioorg Med Chem Lett 26: 1073-1079, 2016.

15. Telford WG, King LE and Fraker PJ: Comparative evaluation of several DNA binding dyes in the detection of apoptosis-associated chromatin degradation by flow cytometry. Cytometry 13: 137-143, 1992.

16. Wang SW and Sun YM: The IL-6/JAK/STAT3 pathway: Potential therapeutic strategies in treating colorectal cancer (Review). Int J Oncol 44: 1032-1040, 2014.

17. Shinagawa K, Yanamoto S, Naruse T, Kawakita A, Morishita K, Sakamoto Y, Rokutanda S and Umeda M: Clinical roles of interleukin-6 and STAT3 in oral squamous cell carcinoma. Pathol Oncol Res 23: 425-431, 2017.

18. Ni CW, Hsieh HJ, Chao YJ and Wang DL: Interleukin-6-induced JAK2/STAT3 signaling pathway in endothelial cells is suppressed by hemodynamic flow. Am J Physiol Cell Physiol 287: C771-C780, 2004.

19. Zhang HF and Lai R: STAT3 in cancer-friend or foe? Cancers (Basel) 6: 1408-1440, 2014.

20. Aravantinos G and Pectasides D: Bevacizumab in combination with chemotherapy for the treatment of advanced ovarian cancer: A systematic review. J Ovarian Res 7: 57, 2014.

21. Sopik V, Rosen B, Giannakeas V and Narod SA: Why have ovarian cancer mortality rates declined? Part III. Prospects for the future. Gynecol Oncol 138: 757-761, 2015.

22. Liu J and Matulonis UA: New strategies in ovarian cancer: Translating the molecular complexity of ovarian cancer into treatment advances. Clin Cancer Res 20: 5150-5156, 2014

23. Kiraz Y, Adan A, Kartal Yandim M and Baran Y: Major apoptotic mechanisms and genes involved in apoptosis. Tumour Biol 37: 8471-8486, 2016.

24. Lesinski GB, Raig ET, Guenterberg K, Brown L, Go MR, Shah NN, Lewis A, Quimper M, Hade E, Young G, et al: IFN-alpha and bortezomib overcome $\mathrm{Bcl}-2$ and $\mathrm{Mcl}-1$ overexpression in melanoma cells by stimulating the extrinsic pathway of apoptosis. Cancer Res 68: 8351-8360, 2008.

25. Fadeel B and Orrenius S: Apoptosis: A basic biological phenomenon with wide-ranging implications in human disease. J Intern Med 258: 479-517, 2005.

26. Hata AN, Engelman JA and Faber AC: The BCL2 Family: Key mediators of the apoptotic response to targeted anticancer therapeutics. Cancer Discov 5: 475-487, 2015.

27. Imada K and Leonard WJ: The Jak-STAT pathway. Mol Immunol 37: 1-11, 2000.

28. Matsui $\mathrm{F}$ and Meldrum KK: The role of the Janus kinase family/signal transducer and activator of transcription signaling pathway in fibrotic renal disease. J Surg Res 178: 339-345, 2012.

29. Wang X, Crowe PJ, Goldstein D and Yang JL: STAT3 inhibition, a novel approach to enhancing targeted therapy in human cancers (Review). Int J Oncol 41: 1181-1191, 2012.

30. Jung IH, Choi JH, Chung YY, Lim GL, Park YN and Park SW: Predominant activation of JAK/STAT3 pathway by interleukin-6 is implicated in hepatocarcinogenesis. Neoplasia 17: 586-597, 2015.

31. Kitamura H, Kamon H, Sawa S, Park SJ, Katunuma N, Ishihara K, Murakami M and Hirano T: IL-6-STAT3 controls intracellular MHC class II alphabeta dimer level through cathepsin S activity in dendritic cells. Immunity 23: 491-502, 2005.

32. Knüpfer H and Preiss R: Serum interleukin-6 levels in colorectal cancer patients--a summary of published results. Int J Colorectal Dis 25: 135-140, 2010.

33. Chung CD, Liao J, Liu B, Rao X, Jay P, Berta P and Shuai K: Specific inhibition of Stat 3 signal transduction by PIAS3. Science 278: 1803-1805, 1997.

34. Kim JH, Jeong HR, Jung DW, Yoon HB, Kim SY, Kim HJ, Lee KT, Gadotti VM, Huang J, Zhang FX, et al: Synthesis and biological evaluation of fluoro-substituted 3,4-dihydroquinazoline derivatives for cytotoxic and analgesic effects. Bioorg Med Chem 25: 4656-4664, 2017. 